\title{
RESEARCH DIRECTIONS
}

\section{Exploring student perceptions of health and infection: an interactive staff and student partnership scheme}

\author{
Abdul Yekeen, AF, Bell, J, Boorman, A, Hancock, C, Kelly, A*, Kelly, E, Mulrooney, HM, \& \\ Streich, R
}

School of Life Sciences, Pharmacy \& Chemistry, Kingston University, Penrhyn Road, Kingston-uponThames, London KT1 2EE.

${ }^{*}$ Corresponding author: a.kelly@kingston.ac.uk

Keywords: partnership, cross disciplinary, health, active learning, wellbeing

\begin{abstract}
Personal health \& wellbeing are rated more highly in those with higher educational qualifications than those without, and good health \& wellbeing are likely to impact upon student attendance and hence attainment at university. It is important to understand factors which may affect perceived health and wellbeing from a student perspective in order to develop university-specific campaigns to correct misinformation. In addition, multidisciplinary working is characteristic in the post-graduation world, but is difficult to truly replicate within formal university teaching. This project had two aims. First, through a crossdisciplinary staff-student collaboration, to explore student perceptions of health and wellbeing in Kingston University. Second, to enable students from a range of disciplines to work in active partnership with each other and with academic staff. A quiz was completed by almost 300 undergraduate students. Results from this and focus group discussions demonstrated reasonable knowledge of a range of lifestyle risk factors affecting health, but misinformation about the safety of vaccines and the importance of nutrition, activity and adequate sleep for maximising health, wellbeing and thus, potentially, university attainment. Future work is planned with Kingston University undergraduate students to address identified misconceptions. Student partners highly rated the opportunity for active
\end{abstract}

learning, partnership working with staff and being part of a cross-disciplinary project team.

\section{Background}

Attainment and achievement at university are impacted upon by health and wellbeing. Poor health, for example as a result of frequent or recurrent infections, is likely to negatively impact upon student attendance, participation and, potentially, attainment. Groups of young people are vulnerable to the spread of infectious disease, and undergraduates are such a group. Many are living away from home for the first time, often in communal accommodation, and they may have unhealthy lifestyle habits and make poor health choices (Dodd et al., 2010; Tully et al., 2006). Recently a new immunisation for young people to protect against meningitis $\mathrm{W}$ was introduced (PHE, 2015); however anecdotally knowledge of this new vaccine appears low. In addition, inappropriate use of antibiotics (e.g. for viral infections) is recognised as a national public health issue. Exploring student knowledge and perceptions of the causes and prevention of, as well as treatments for, infectious disease is important. Campaigns to minimise inappropriate use of antibiotics, as well as those to minimise the spread of infectious diseases can be targeted suitably through vaccinations in a key vulnerable group. In addition understanding student knowledge and beliefs may help University healthcare services to focus specifically on beliefs and practices 
likely to reduce the spread of infectious diseases, thereby potentially benefitting student attendance and ultimately attainment. This may have a disproportionately beneficial effect in those groups where attainment is currently lower than expected. National data from 2013-14 shows an attainment gap between BME and white students of $15.2 \%$ (ECU, 2015) and in line with national figures, attainment among BME students at Kingston University $(\mathrm{KU})$ is lower than would be expected. Although this has fallen over time, reducing the attainment gap is a $\mathrm{KU}$ priority since educational attainment and qualifications achieved are an indicator of future employment and income (ONS, 2016), which also correlates to improved health and wellbeing. Those with higher qualifications were more likely to rate their life satisfaction as high compared to those with low qualifications (ONS, 2016). Health, wellbeing and educational attainment are linked; therefore one aim of this project was to explore student beliefs, knowledge and lifestyle practices in relation to the risk of infection. Additionally, cross-disciplinary working is a normal part of the working life of many graduates, sharing skills and attributes with others as part of multidisciplinary teams. However, opportunities for cross-disciplinary sharing and learning at undergraduate level can be limited. Although many students attend lectures with students from other degree pathways, they lack the opportunity within formal teaching time to truly share ideas, understand each other's perspectives and learn from each other through shared work. It is likely that students from different disciplines will have different knowledge, beliefs and attitudes and this valuable opportunity to benefit from cross discipline peer-learning is lost. This project therefore also aimed to promote cross-disciplinary active student learning within a small staff- student research team. Within KU, the Student Academic Development Research Associate Scheme (SADRAS) is a university-wide scheme which promotes educational development projects in which students play an active part (https://mykingston.kingston.ac.uk/myfaculty/f ada/Pages/SADRAS.aspx). It enables student and staff partners to work together equally on specific projects, and SADRAS students are funded for their participation. Involvement of staff in active learning has been shown to be important in that teachers create the conditions in which learning is possible (Mueller \& Fleming, 2001). The staff-student partnership therefore represented an ideal opportunity to develop this project.

\section{Methods}

\section{Establishing the project}

SADRAS funding was successfully obtained for student partners.

The opportunity to participate in the SADRAS project was advertised to undergraduate students on Infection \& Immunity, a Level 5 module. This module was chosen as it is core for all students from five different undergraduate degree pathways. Twenty interested students applied and were offered the opportunity to meet and discuss their initial ideas with staff partners. Of the initial twenty, six applicants gave excellent presentations and were successful in their applications. They were all second year students studying BSc Nutrition (2 students), Medical Biochemistry, Biological Sciences, Pharmacology and Biomedical Science (1 student each).

\section{Ethics approval}

Ethics approval for the project was obtained from Kingston University CHERP (Centre for Higher Education Research \& Practice) Research Ethics Committee prior to commencement of the project.

\section{Quiz development}

Student partners, with staff help, developed a quiz to explore student perceptions of health and disease, including lifestyle risk factors and their impact on health. This comprised a mixture of questions and statements with which participants could agree or disagree. All questions and statements were based on factors which were considered to potentially affect student attainment.

The quiz was divided into four main sections: health perceptions and beliefs; key lifestyle behaviours such as smoking, alcohol consumption, sleep, diet, physical activity; infection spread and control including vaccination; and, lastly, cleanliness and health status. Participants were also asked to identify which specific illnesses they thought were most likely to affect student groups. 
Finally, participants were asked to fill in their student identification number, which enabled staff partners to access their online profile and identify key demographic information. This included age, gender, ethnicity, whether they lived at home or away while at university and their degree pathways. Because quizzes were distributed in class, the year of study was already known. Staff partners uploaded personal data into a spreadsheet, removed the university identification numbers and only then was the anonymised dataset shared with student partners for analysis. This ensured anonymity of participants among their peers.

\section{Quiz distribution}

For feasibility, quizzes were distributed in class in modules attended by students studying a range of degree programmes within the School of Life Sciences, Pharmacy \& Chemistry. Key modules were chosen in order to obtain representation from large numbers of students within the School. All participants were given an information sheet before the quiz was distributed; completion of the quiz was optional.

\section{Focus groups}

Qualitative information was also sought using focus groups to explore key themes in more detail. A focus group guide with key questions was developed collaboratively by staff \& student partners, and all participants completing the quiz were offered the opportunity to participate in a focus group. The focus group guide contained 5 questions, which were discussed in turn. Discussions were monitored by two student SADRAS partners and audiotaped for basic thematic analysis. Focus groups were held in the Nutrition Kitchen at the university, a small bespoke kitchen used for group work, and basic refreshments were provided.

\section{Cross-disciplinary working of the project}

Student SADRAS partners established a WhatsApp group to communicate with each other. They met frequently and maintained excellent communications throughout the project with staff partners. There were few formal meetings with staff partners but several informal discussions and online conversations. Student partners agreed task allocation among themselves. Staff partners arranged for photocopying of the quizzes and permission from teaching staff to disseminate quizzes inclass where necessary. Student partners prepared an Excel spreadsheet into which all data was entered including the unique university identification number for each participant. When complete staff partners used the unique identifiers to enter personally identifiable data into the Excel spreadsheet, and the identification number was removed. Age, gender, ethnicity and living status (home or away) was entered for each participant, and the anonymised spreadsheet was then shared with student partners for analysis.

\section{Data analysis}

Using the Excel spreadsheet, perceptions, beliefs and knowledge of participants was explored. This included differences in responses within different year groups, and between gender, ethnicity and living status. Basic statistical analysis (groupings and averages) was carried out.

\section{Student \& staff partner experience}

Student and staff partners also completed a short questionnaire to identify their reasons for participation, what they learnt from the project and how they would apply this knowledge in future. From this data, the most common themes for both were identified.

\section{Results}

\section{Quiz dissemination}

More than 300 questionnaires were disseminated within core undergraduate modules. Of these 273 were completed in full and included in the study (approximately 50 were spoiled or incomplete and not used).

\section{Respondents}

The majority of participants were females, representing $86 \%$ of total participants. Gender discrepancy was most marked in Level 5 where only $2 \%$ of respondents were male. Students across all three year groups were represented although smaller numbers of final year students participated $(34 \%, 38.5 \%$ \& $27.5 \%$ of participants from Levels $4,5 \& 6$ respectively). Participants represented all ethnicities; reflecting the multi-ethnic breakdown of the $\mathrm{KU}$ student body (approximately 50\% BME). Numbers of Black respondents were lower than numbers of White or Asian students but 
were consistently low across all year groups. Numbers of Asian respondents were highest at level 5 (Figure 1).

\section{Quiz responses \\ Beliefs}

Across all year groups students agreed that increased stress had a negative impact on overall health with $96 \%$ to $99 \%$ respondents from Level 4 to Level 6 respectively agreeing with this statement.

In terms of perceived effects of accommodation, the majority of participants agreed that where one lives impacts on the risk of illness $(65 \%$ of Level $4(n=93), 76 \%$ of Level $5 \quad(n=105)$ and $85 \%$ of Level $6 \quad(n=75)$ respectively).

Whilst there was also broad agreement across all year groups that nutrition affected success and attainment at university (Figure 2), approximately a third of respondents disagreed with this statement.

Older students were more likely to agree that health was important while studying for a degree, with $97 \%$ of Level 6 and $95 \%$ of Level 5 students agreeing with this statement (Figure $3)$. In contrast, only $71 \%$ of Level 4 students agreed.

\section{Attitudes}

Attitudes to vaccines were found to vary both within and between year groups. At Level 4, $42 \%$ of students agreed with the statement 'vaccines can cause harm', compared with $36 \%$ of Level 5 and $27 \%$ of Level 6 students. However, there was marked uncertainty in relation to this issue especially in Level 5 students, with $55 \%$ indicating that they were unsure.

\section{Knowledge}

Good awareness of the importance of microorganisms in human health \& antibiotic resistance was found in all year groups. Awareness that specific vaccines are offered to students in the UK was highest in Level 4 students (61\%) and lowest in Level 5 students (28\%). Awareness of student-specific vaccines was also low in Level 6 (48\%).

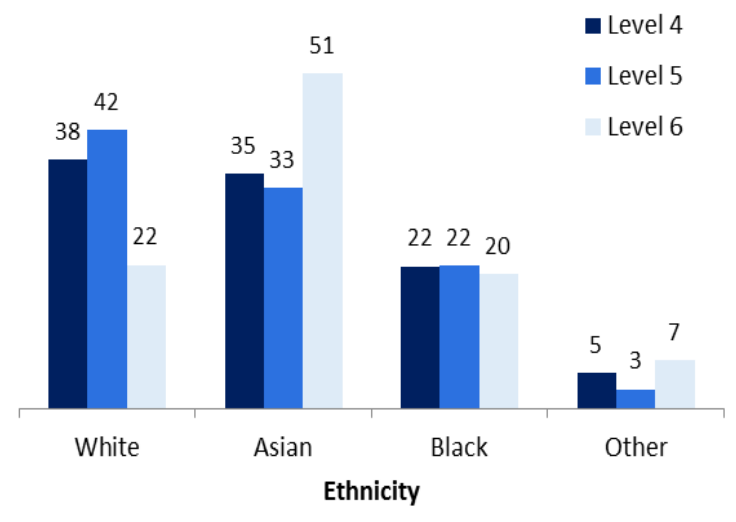

Figure 1 Ethnic breakdown of questionnaire respondents by year of study and ethnic group (\%)

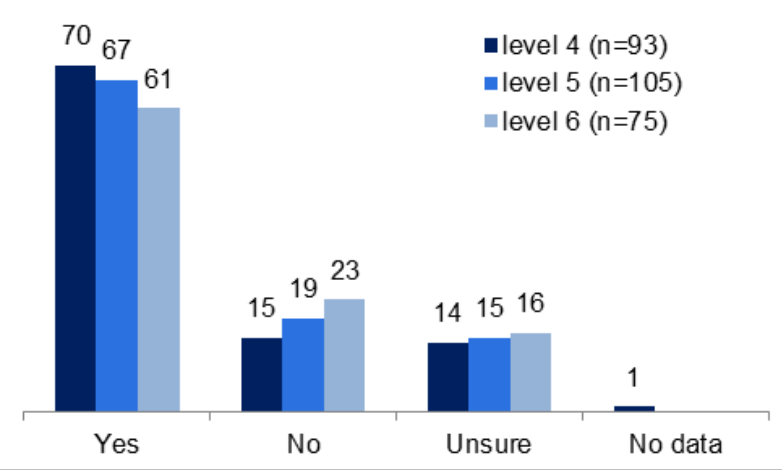

Figure 2 Responses across year groups to the statement: What you eat affects your success/achievement at university (\%)

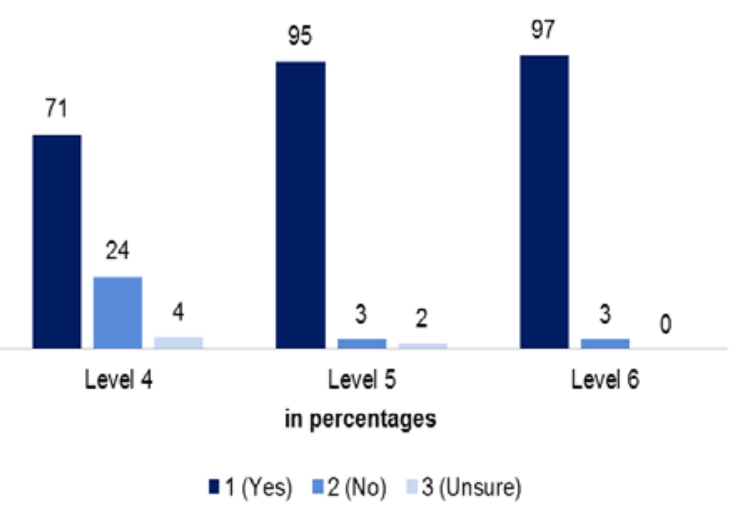

Figure 3 Responses across year groups to the statement: Your health status is important while you are studying for a degree 
Exploring student perceptions of health and infection: an interactive staff and student partnership scheme

\section{Illnesses}

Students were asked to identify all infections or illnesses that in their opinion, potentially affected students. There was no limit to the number of illnesses they could identify. The main ones are shown in Table 1. A total of 388 illnesses were identified, of which $30 \%$ were sexually transmitted infections. There was strong awareness of the risk posed by viral infections such as colds \& flu ( $n=91$ or $23 \%$ of overall responses). Awareness of meningitis was highest in the first years, while both stress and mental health were identified most often by Level 5 participants.

\begin{tabular}{|l|c|c|c|c|}
\hline $\begin{array}{l}\text { What illness/infection do you think } \\
\text { students are at greater risk of? }\end{array}$ & $\begin{array}{c}\text { Level 4 } \\
\text { Number } \\
\text { (\%) }\end{array}$ & $\begin{array}{c}\text { Level 5 } \\
\text { Number } \\
\text { (\%) }\end{array}$ & $\begin{array}{c}\text { Level 6 } \\
\text { Number } \\
\text { (\%) }\end{array}$ & $\begin{array}{c}\text { Total Number } \\
\text { (\%) }\end{array}$ \\
\hline Sexually transmitted infections (STI) & $32(26)$ & $27(17.6)$ & $59(52)$ & $118(30)$ \\
\hline Colds/flu/chest infections & $43(35)$ & $13(8.5)$ & $35(31)$ & $91(23)$ \\
\hline Other e.g. vitamin deficiency & $12(31)$ & $20(51)$ & $7(18)$ & $39(10)$ \\
\hline Mental health & $9(7)$ & $21(14)$ & $3(2.7)$ & $33(8.5)$ \\
\hline Stress & $5(4)$ & $24(15.6)$ & $2(1.8)$ & $31(8)$ \\
\hline Meningitis & $15(12)$ & $3(2)$ & $1(0.9)$ & $19(5)$ \\
\hline Not answered/unsure & $0(0)$ & $13(8.5)$ & $4(3.5)$ & $17(4)$ \\
\hline Alcohol (related illness) & $1(0.8)$ & $10(6.5)$ & $1(0.9)$ & $12(3)$ \\
\hline Sleep (lack of) & $1(0.8)$ & $10(6.5)$ & $0(0)$ & $11(3)$ \\
\hline Obesity /raised cholesterol & $3(2.5)$ & $5(3)$ & $1(0.9)$ & $9(2)$ \\
\hline Close contact & $1(0.8)$ & $7(4.6)$ & $0(0)$ & $8(2)$ \\
\hline Total number of responses (n) & $122(31)$ & $153(39)$ & $113(29)$ & $388(100)$ \\
\hline
\end{tabular}

Table 1 Illnesses particularly thought to affect students, identified by participants and year of study

\section{Focus groups}

A single focus group was undertaken with Level 5 students. Major themes which emerged were stress and coping mechanisms. Stress was viewed both as a positive and negative force for achievement; students recognised stress as natural, but excessive stress had a negative impact. A support network of friends as well as exercise and fresh air were identified as coping mechanisms to lessen the impact of stress. Additional coping mechanisms include time management, identification of own learning styles and goal-setting. The role of family in terms of causing, sustaining or alleviating stress levels was also discussed. Missing lectures and travel when unwell were identified as reasons for non-attendance. This was particularly the case when the illness was considered contagious.

\section{Cross-disciplinary working of the project}

A contemporaneous blog was completed by student partners. They met frequently and by using the WhatsApp group communicated well with each other. Task division appeared to be reasonably equitable although it became clear early on that a core group of four of the six students was driving the project forward. Communication with staff was excellent throughout, aided by the fact that these students were taught by the staff partners, hence were in regular contact.

\section{Staff and student partner experience}

Both staff members and three of the six student participants answered the three questions (respectively why did you participate, what did you learn \& how will you apply it). This data was entered into WorditOut (https://worditout.com/), to generate wordclouds for both student and staff partners. Student partners identified their most common reasons for participating as working with academic staff and gaining experience for their $\mathrm{CV}$ as well as research experience. In terms of what they learnt, time management, data 
handling (including collection, manipulation and analysis), questionnaire development and group working were most commonly identified (Figure 4).

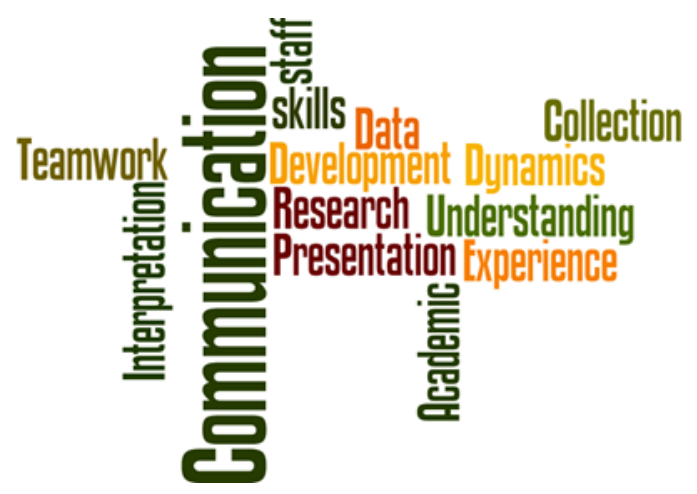

Figure 4 Amalgamated 'What I have learnt \& gained' responses from student partners.

Thinking of how to apply these skills, students identified both their final year of study and their future working lives.

For staff, the chance to work with new partners (both staff and students) as well as academic curiosity about the subject were key reasons to become involved. Managing the group and time management, as well as taking risks with the project were identified as key staff learnings, and, in terms of gains, new partners to work with and new research areas with novel ideas were identified.

\section{Discussion}

\section{Staff: student partnership working:}

This project represented an educational opportunity which could be characterised as peer, student-centred and active learning. The six student partners, initially identified at the start of the project by their levels of engagement, brainstormed topics, and developed and disseminated the quiz, in addition to analysing the data and preparing the project poster. Peer learning is identified in the pedagogic literature as beneficial, enhancing cognition and collaboration in learning (Vygotsky, 1978; Slavin, 1996; Boud et al, 2001). In addition, the use of active learning i.e. the attainment of knowledge by participating or contributing (Collins \& O'Brien, 2003) is also supported within the literature (Modell \& Michael, 1993; Prince, 2004).
Participants reported they learnt better when they were able to 'do something' rather than just 'reading the textbook' (Mueller \& Fleming, 2001). Adult learners are reported to require active, purposeful learning activities with clear goals and objectives, opportunities for reflection and feedback (Brookfield, 1998). In student-centred learning, student behaviour is a major determinant of what is being learned (Barr \& Tagg, 1995). The student at the centre of the learning process can influence the activity, pace and content of learning (Collins \& O'Brien, 2003), and is more likely to achieve meaningful learning as a result (Michael, 2001, 2004; Novak, 2002). Whilst our project encouraged collaborative and active learning, student behaviour is another factor in any collaboration. Having a group that worked together as well as this one did was not just fortuitous. The initial step requiring interested students to think about what they would bring to the project made identification of truly engaged students easier right from the beginning. Although a core group of four highly motivated students drove the project forward, it is not unusual to have leaders within any group. What was perhaps more surprising was that relationships within that group of four remained harmonious throughout. The crossdisciplinary nature of the group was apparent in the quiz developed by the students; the range of questions considered encompassed different perspectives. Exposure to each other's thinking is likely to benefit the group, particularly in their future careers, and students themselves identified both their final year in university and their future working lives as arenas where they could utilise the skills and knowledge gained from this project.

Partnership with staff was also identified by students as an important reason for involvement in the project. Partnership working was a general theme of the SADRAS initiative; from the staff perspective, working with students in a less formal and more equitable way was exciting and motivating, while the staff-staff partnership itself generated new ideas for future collaborations.

\section{Perceptions of health \& infection:}

From this work, it seems clear that knowledge, attitudes and beliefs of students need to be addressed by a variety of means to reduce their risks of ill health thereby increasing their 
Exploring student perceptions of health and infection: an interactive staff and student partnership scheme

potential for academic achievement. Awareness of sexually transmitted infections as a potential risk was high in all year groups. However many students appeared unaware of the reciprocal links between good health and attainment, or that lifestyle factors like good nutrition, adequate sleep, and being active are all essential to maintaining health so that time at university can be academically maximised.

To build upon this project, future work within existing $\mathrm{KU}$ events is planned, for example working with the KU University Health Week team to develop a KU-specific campaign raising awareness of factors affecting risk of illness in students. In addition, Welcome Week would be an ideal time to target new first year students arriving for induction, and the initial lecture in the Infection and Immunity module would be a worthwhile avenue to reach large groups of second year students and reinforce health messages. Future project work with student partners is underway to explore qualitative aspects in more detail and with a greater range of year groups. It was only possible to carry out one focus group within this project, and a greater number will allow more in-depth exploration of student knowledge, beliefs and attitudes. In addition student awareness of relevant support services available within the university setting is an important potential mitigator against unhealthy lifestyle practices. Student awareness of these services will also be explored.

\section{Conclusion}

The experience of working in a collaborative active partnership was positive for both staff and students, albeit for different reasons. Within a large sample of undergraduate students, awareness of some aspects of healthy lifestyle appeared to be low, and beliefs about vaccines were mixed. Future work to explore these findings in more detail is currently underway.

\section{References}

Barr, R.B. \& Tagg, J. (1995) From teaching to learning - a new paradigm for undergraduate education. Change 27 (6), 13-25.
Boud, D., Cohen, R. \& Sampson, J. (2001) Peer learning in higher education: learning from and with each other. Kogan Page Ltd: UK.

Brookfield, S. (1998) Understanding and facilitating adult learning. Oxford University Press: Milton Keynes.

Collins, J.W. $3^{\text {rd }} \&$ O'Brien, N.P. (2003) (eds) The Greenwood Dictionary of Education. Greenwood: Westport CT.

Dodd, L.J., Al-Nakeeb, Y., Nevill, A. \& Forshaw, M.J. (2010) Lifestyle risk factors of students: A cluster analytical approach. Preventative Medicine 51, 73-77. http://dx.doi.org/10.1016/j.ypmed.2010.04.005

Equality Challenge Unit (2015) Equality in higher education: statistical report 2015. Part 2: students. Available from:

http://www.ecu.ac.uk/wpcontent/uploads/2015/11/Equality-in-HEstatistical-report-2015-part-2-students.pdf (last accessed 08/09/2016).

Michael, J.A. (2001) In pursuit of meaningful learning. Advances in Physiology Education 25, 145-158. URL (last accessed 08/09/16): http://advan.physiology.org/content/ajpadvan/ 25/3/145.full.pdf

Michael, J.A. (2004) Mental models and meaningful learning. Journal of Veterinary Medical Education 31, 1-5.

Modell, H.I. \& Michael, J.A. (1993) Promoting active learning in the life sciences classroom: defining the issues. Annals of the New York Academy of Sciences 701, 1-7.

DOI: 10.1111/j.1749-6632.1993.tb19770.x

Mueller, A. \& Fleming, T. (2001) Cooperative learning: listening to how children work at school. Journal of Educational Research 94 (5), 259-265

Novak, J.D. (2002) Meaningful learning: the essential factor for conceptual change in limited or inappropriate propositional hierarchies leading to empowerment of learners. Science Education 86, 548-571.

DOI: $10.1002 /$ sce.10032 
Office for National Statistics (2016) Measuring national wellbeing: Life in the UK: 2016. Available from:

http://www.ons.gov.uk/peoplepopulationandco mmunity/wellbeing/articles/measuringnational wellbeing/2016\#how-skilled-are-we (last accessed 08/09/2016)

Prince, M. (2004) Does active learning work? A review of the research. Journal of Engineering Education 93 (3), 223-231.

DOI: 10.1002/j.2168-9830.2004.tb00809.x

Public Health England (2015) New meningococcal vaccination programme expected to save lives. Available from: https://www.gov.uk/government/news/newmeningococcal-vaccination-programmeexpected-to-save-lives (last accessed October 2015)
Slavin, R.E. (1996) Research on cooperative learning and achievement: what we know, what we need to know. Contemporary Educational Psychology 21, 43-69.

DOI: 10.1006/ceps.1996.0004

Tully, J., Viner, R.M., Coen, P.G., Stuart, J.M., Zambon, M., Peckham, C., Booth, C., Klein, N., Kaczmarski, E. \& Booy, R. (2006). Risk and protective factors for meningococcal disease in adolescents: matched cohort study. British Medical Journal.

DOI:10.1136/bmj.38725.728472.BE

Vygotsky, L.S. (1978) Mind in society. In: Cole M, John-Steiner V, Scribner S \& Souberman E (Eds). Cambridge MA: Harvard University Press. 